\title{
Structure of Cellulose
}

$\mathrm{T}$ HE recent annual Convention of the Technical Section of the Paper Makers' Association of Great Britain was unusual in that the subject chosen was one which appeared at first sight to be more of academic than of practical interest. Fortunately, in the able hands of Prof. H. Mark, of the University of Vienna, who opened the conference, the subject lost many of its complexities, and technical men present were stimulated to attempt to apply theory to their practical problems.

Prof. Mark's paper, which is published in a special issue of the World's Paper Trade Review, dealt principally with the structure of cellulose. He supported the theory, now generally accepted, that cellulose is built up of so-called micelles consisting of bundles of parallel chains of glucose molecules, and he dwelt at some length on the controversy which at present concerns the actual length of these chains. The majority of the evidence, including that based on the chemical properties of cellulose, points to a length of 150-200 glucose units, and yet one cannot ignore the work of Staudinger on viscosity, which can only be explained by a much higher figure. It may be that the lower figure represents a minimum value.

In opening the general discussion, Sir William Bragg referred to the X-ray evidence on which so much of this work is based. Subsequent speakers paid some attention to the much-debated question of the mechanism of the hydration which occurs when paper is beaten, and a suggestion was made that the resulting change in structure is analogous to that which occurs in the manufacture of true cellulose plastics by chemical reaction.

Prof. Mark also indicated how such theories might be applied to problems in the art-silk industry, although it seems that they can do little at present to explain what occurs when cellulose is beaten for paper-making, as this problem is concerned with water absorption rather than with modification of crystalline structure. When, for example, a silk fibre is bent, the outer layers are stressed more than the inner core, and so long as the elastic limit of the latter is not surpassed the fibre will return to its original position and will thus show resistance to creasing. Unfortunately, this resistance is usually decreased when a fibre is treated so as to increase its tensile strength, but it is now possible to obtain the core more highly orientated than the surface and so to preserve both properties. Here one can take a leaf from the book of Nature, since this difference in orientation is already present in the natural silk fibre. If, however, the silkworm is placed on a revolving rod, and is therefore compelled to spin more rapidly, it descends to the level of human endeavour so far as lack of creasing-resistance of its product is concerned.

Prof. Mark obviously voiced the opinion of those present when he stated that the interaction of water and cellulose is one of the most interesting questions in paper-making. He chose to approach the problem by taking absorption capacity as an index of changes produced in the area and quality of the surface of the fibre by chemical treatment or by beating. His results indicate that hydroxyl groups are responsible for the fixation of water molecules on the surface of the cellulose, and act by virtue of the secondary valencies of the oxygen atoms; treatment with a chemical reagent opens up small slits or holes in the micelle into which further molecules of water may pass. Penetrations of solvents and swelling agents into the cellulose lattice is not unknown, but as a rule X-rays show evidence of well-defined addition compounds. Until now, however, no one has succeeded in preparing a true cellulose hydrate, so that an important link in an otherwise strong chain of evidence is still missing.

\section{Sunspots and Meteorological Phenomena}

$\mathrm{I}^{\mathrm{N}}$ a monograph entitled "L'Influence Solaire et les Progrès de la Météorologie"* Henri Memery advances the theory that sunspots show a tendency to increase and decrease at certain definite times of the year, and that this tendency is shown whatever period of years is considered. He suggests further that there is a relationship between the amount of sunspot development and numerous terrestrial disturbances, for example, spells of abnormal rainfall and temperature, and also between individual groups of sunspots and meteorological phenomena. Fifty years of solar and meteorological observations made at the Observatoire de Physique solaire et de Météorologie, Talence, provide a large part of the experimental data on which his views are based.

To most astronomers and meteorologists, the theory that sunspot activity shows any permanent relationship with the dates on our terrestrial calendar will probably appear a highly improbable one, to be accepted only in the face of overwhelming evidence of

- I'Influence solaire et les progrès de la météorologie: résultats de 50 années d'observations solaires et météorologiques comprenant les observations et les recherches effectuées à Talence à partir de 1900 Par Henri Mémery. Pp.iv + 23. (Talence : Observatoire de Physique solaire et de Météorologie, 1932. its truth. The evidence in this paper rests upon curves showing the average area on the sun's disc covered by sunspots on each day of the year for periods of 12,41 and 50 years. There are, however, apparent discrepancies between the lengths of the periods implied by the statements made alongside these curves and those given above the curves. The periods are quoted as 12,40 and 50 years in the latter case and it is possible that 40 should replace 41 in the algebraic expressions given below. It will be seen, however, that the conclusions reached are not affected by this uncertainty, nor even by the doubt as to whether the 12 year period should not have been taken as 13 years. Few would deny that the three curves show considerable similarity, but the periods covered are 1889-1901, 1880-1920, and $1880-1929$, that is, the 12 years in the first group are used also in the groups for 41 and 50 years, and the overlap is even greater for the 41 and 50 year means.

The question arises whether the similarity in the curves cannot be explained simply by this overlap. Take the case of the curves for 12 and 41 year periods. The similarity between these is held to imply a positive correlation between the ordinates. The two 
variables are $x_{1}$, and $\left(12 x_{1}+29 x_{2}\right) / 41$ where $x_{1}$ and $x_{2}$ are the means for the common period of 12 years and for the remaining 29 years of the 41 year period, respectively. The correlation between $x_{1}$ and $12 x_{1} / 41$ is of course unity, and, unless it is true that the shapes of the annual sunspot curves obtained by using entirely separate series of years are similar, the correlation between $x_{1}$ and $\left(12 x_{1}+29 x_{2}\right) / 41$ will by a well-known statistical formula bear the same ratio to unity as does the standard deviation of $12 x_{1} / 41$ to the standard deviation of $\left(12 x_{1}+29 x_{y}\right) / 41$. This correlation coefficient works out to $+0 \cdot 38$.

The correlation coefficient between the 12 and 41 year mean curves was then determined, using the ordinates of the two curves at the beginning and middle of each month. The figure found was $+0 \cdot 38$, that is, exactly that which is to be expected solely from the overlap. (The exact agreement between the two coefficients must of course be accidental. Had the experimental figure been even +0.5 or +0.6 the evidence that the overlap was not the cause of the similarity would still have been inadequate, but with a coefficient of +0.8 or more the author's claim would have been well supported.) A similar analysis could be applied to the other pairs of curves, but it has been deemed sufficient to show by a single random test that a faulty method has been used with misleading results. Although no further example of overlapping is evident in the comparative curves illustrating the other relationships claimed in this paper, the method adopted throughout has been to give purely statistical evidence for alleged physical relationships in such a way that a critical reader cannot see, until after considerable mathematical analysis of this evidence, whether the latter does in fact give any support for the supposed relationships.

It seems safe to conclude that most astronomers and meteorologists will not accept the author's ideas until more up-to-date statistical methods are used.

E. V. N.

\section{Atmospherics Research in the Southern Hemisphere}

A FEW years ago the Australian Council for Scientific and Industrial Research established a Radio Research Board to conduct scientific and technical research into some of the more fundamental problems associated with radio communication. Amongst the items of work which it was planned to carry out were the repetition of some of the investi. gations already in progress in Great Britain under the British Radio Research Board, with the view of obtaining a direct comparison of the propagation of electric waves in the two hemispheres. As a useful aid in this matter some of the investigators appointed in Australia had the advantage of receiving their training in radio research under the organisation in Great Britain. The results of the work already carried out in Australia are being published in a series of special reports, and the latest of these is entitled "Atmospherics in Australia (I)".* This report contains the results of observations made chiefly by means of two cathode ray oscillograph direction-finders supplied by the British Radio Research Station at Slough, where this type of instrument has been developed to a high degree.

The first series of observations were made on board the s.s. Baradine, in December 1929 and January 1930, when Messrs. Munro and Huxley were on their way to Australia to take up their appointments. After setting up the apparatus on board, observations were made on the transmissions from a number of European stations to enable a calibration curve to be obtained showing the error in apparent direction of arrival of the waves caused by the metal work of the ship. Regular daily observations on atmospherics were commenced one day before reaching Port Said and were continued during the remainder of the voyage. From the indications on the cathode ray oscillograph screen, both the true direction of arrival and the strength of each atmospheric was recorded. These observations, which were carried out on a wave-length of $30 \mathrm{~km}$., supplied very definite evidence in favour of a thunderstorm origin for atmospherics. The directions, as recorded on the voyage through the Red Sea and across the. Indian Ocean, converged on an area in Central

* G. H. Munro and L. G. H. Huxley: "Atmospherics in Australia. (I)". Radio Research Board, Report No. 5. Melbonme. 1932.
Africa which is known to be the most active thunderstorm area in the world. Beyond Colombo, the directions of most of the other sources of atmospherics observed passed through other active thunderstorm areas in the East Indies and Northern Australia. Round the south coast of Australia, the predominant sources appeared to be within, or near to, the north of the continent.

On arrival in Australia, the apparatus used on the ship was installed near Melbourne for preliminary observations. Towards the end of 1930, a second cathode ray direction-finder arrived in Australia and was set up on a selected site about three hundred miles from the first instrument. The circuit arrangement of each instrument was modified to make the oscillograph unidirectional in its indications, and a short. wave wireless link was provided between the two stations so that simultaneous recording of the direction and intensity of individual atmospherics could be carried out; and such observations were commenced in March 1931. The majority of these observations were carried out on a wave-length of $3 \mathrm{~km}$. as it was thus found possible to restrict the range from which atmospherics were received to about 2,000 miles, whereas on a wave-length of $30 \mathrm{~km}$. the range was at least 5,000 miles. The origins of the atmospherics observed were located by taking simultaneous bearings at the two stations. Systematic observations taken in this manner on a wave-length of $3 \mathrm{~km}$. showed that the range of intensities, when corrected for the distance travelled and the attenuation in the path, was quite small, being of the order of 4 to 1 ; and also that the intensity distribution about the mean was a normal probability one.

A large proportion of the atmospheric sources located were within the Australian continent itself. The small range of intensities noted above suggests a similar origin for all the atmospherics observed, and this has been confirmed by the correlation found between the indicated sources of the atmospherics and those of the thunderstorms located through the normal meteorological observation network. The authors conclude from their investigations that all the atmospherics observed had their origins in lightning strokes occurring generally in thunderstorms, 